\title{
The joint IAEA, EANM, and SNMMI practical guidance on peptide receptor radionuclide therapy (PRRNT) in neuroendocrine tumours
}

\author{
John J. Zaknun • L. Bodei • J. Mueller-Brand • \\ M. E. Pavel • R. P. Baum • D. Hörsch • M. S. O'Dorisio • \\ T. M. O'Dorisiol • J. R. Howe • M. Cremonesi • \\ D. J. Kwekkeboom
}

Published online: 7 February 2013

(C) The Author(s) 2013. This article is published with open access at Springerlink.com

\begin{abstract}
Peptide receptor radionuclide therapy (PRRNT) is a molecularly targeted radiation therapy involving the systemic administration of a radiolabelled peptide designed to target with high affinity and specificity receptors overexpressed on tumours. PRRNT employing the radiotagged somatostatin receptor agonists ${ }^{90}$ Y-DOTATOC $\left(\left[{ }^{90} \mathrm{Y}\right.\right.$-DOTA $\left.{ }^{0}, \mathrm{Tyr}^{3}\right]$-octreotide $)$ or ${ }^{177}$ Lu-DOTATATE ( $\left[{ }^{177} \mathrm{Lu}\right.$-DOTA $\left.^{0}, \mathrm{Tyr}^{3}, \mathrm{Thr}^{8}\right]$-octreotide or $\left[{ }^{177} \mathrm{Lu}\right.$-DOTA $\left.{ }^{0}, \mathrm{Tyr}^{3}\right]$-octreotate) have been successfully used for the past 15 years to target metastatic or inoperable neuroendocrine tumours expressing the somatostatin receptor
\end{abstract}

L. Bodei

Division of Nuclear Medicine, European Institute of Oncology,

Milan, Italy

\section{J. J. Zaknun $(\bowtie)$}

Nuclear Medicine Section, Division of Human Health, International Atomic Energy Agency, IAEA, Vienna, Austria

e-mail: J.zaknun@hotmail.com

\section{J. J. Zaknun}

e-mail: John.Zaknun@Zentralklinik.de

\section{J. J. Zaknun}

Zentralklinik Bad Berka, Center for Molecular Radiotherapy and Molecular Imaging, ENETS Center of Excellence, Bad Berka, Germany

J. Mueller-Brand

Klinik und Institut für Nuklearmedizin, Universitätsspital Basel, Basel, Switzerland

\section{E. Pavel}

Campus Virchow Klinikum, Klinik für Gastroenterologie, Hepatologie, Endokrinologie, Diabetes und Stoffwechsel-erkrankungen, Charité Universitaetsmedizin Berlin, Berlin, Germany subtype 2. Accumulated evidence from clinical experience indicates that these tumours can be subjected to a high absorbed dose which leads to partial or complete objective responses in up to $30 \%$ of treated patients. Survival analyses indicate that patients presenting with high tumour receptor expression at study entry and receiving ${ }^{177} \mathrm{Lu}$-DOTATATE or ${ }^{90}$ Y-DOTATOC treatment show significantly higher objective responses, leading to longer survival and improved quality of life. Side effects of PRRNT are typically seen in the kidneys and bone marrow. These, however, are usually mild provided adequate

\section{R. P. Baum · D. Hörsch}

Zentralklinik Bad Berka, Department of Internal Medicine, Gastroenterology and Endocrinology, ENETS Center of Excellence, Bad Berka, Germany

M. S. O'Dorisio

RJ and LA Carver College of Medicine, Department of Pediatrics, University of Iowa, Iowa City, IA, USA

T. M. O'Dorisiol

RJ and LA Carver College of Medicine, Department of Internal Medicine, University of Iowa, Iowa City, IA, USA

\section{J. R. Howe}

RJ and LA Carver College of Medicine, Department of Surgical Oncology, University of Iowa, Iowa City, IA, USA

\section{Cremonesi}

Service of Health Physics, European Institute of Oncology, Milan, Italy

D. J. Kwekkeboom

Department of Nuclear Medicine, Erasmus Medical Center Rotterdam, Rotterdam, The Netherlands 
protective measures are undertaken. Despite the large body of evidence regarding efficacy and clinical safety, PRRNT is still considered an investigational treatment and its implementation must comply with national legislation, and ethical guidelines concerning human therapeutic investigations. This guidance was formulated based on recent literature and leading experts' opinions. It covers the rationale, indications and contraindications for PRRNT, assessment of treatment response and patient follow-up. This document is aimed at guiding nuclear medicine specialists in selecting likely candidates to receive PRRNT and to deliver the treatment in a safe and effective manner. This document is largely based on the book published through a joint international effort under the auspices of the Nuclear Medicine Section of the International Atomic Energy Agency.

Keywords Peptide receptor radionuclide therapy · PRRNT . PRRNT, neuroendocrine tumours, guideline/s, renal protection

\section{Purpose}

This guidance document is aimed at assisting and guiding nuclear medicine specialists in:

1. Assessing patients with neuroendocrine tumours (NETs) for their eligibility to undergo treatment with ${ }^{90} \mathrm{Y}$ - or ${ }^{177}$ Lu-radiolabelled somatostatin analogues.

2. Providing guidance on performing peptide receptor radionuclide therapy (PRRNT) and implementing this treatment in a safe and effective manner.

3. Understanding and evaluating the outcome of PRRNT, namely treatment results and possible side effects including both renal and haematological toxicities.

A committee of international experts was assembled under the auspices of the International Atomic Energy Agency (IAEA), in cooperation with the EANM Therapy, Oncology and Dosimetry Committees and with the Society of Nuclear Medicine and Molecular Imaging. They worked together to create this guidance document on the use of somatostatin analogue-based PRRNT. This guidance document was compiled taking into account recent literature and experts' opinion.

\section{Regulatory issues}

Applicable in all countries Clinicians involved in unsealed source therapy must be knowledgeable about and compliant with all applicable national and local legislation and regulations.

Applicable in the USA The radiopharmaceuticals used for the diagnostic and therapeutic procedures addressed in this guidance document are not approved by the Food and Drug Administration (FDA) in the USA. Therefore in the USA these procedures should be performed only by physicians enrolled in an investigational protocol pursuant to a valid Investigational New Drug application or Radioactive Drug Research Committee approval and under the purview of an appropriate institutional review board.

\section{Background information and definitions}

\section{Definitions}

\section{PRRNT}

Somatostatin

Somatostatin receptors In humans five sstr subtypes have been identified. Each sstr is a transmembrane molecule weighing approximately $80 \mathrm{kDa}$. Somatostatin exerts its action by inhibiting G-protein-dependent 3', $5^{\prime}$ cyclic monophosphate (cAMP) formation in a dose-dependent manner at subnanomolar concentrations. Sstr2 is overexpressed in NETs. Sstr2 is the key target molecule for both cold and radiolabelled SSA. Upon binding to its receptor, the complex (SSA-sstr) undergoes cellular internalization thereby 
enhancing the therapeutic effect of the radiolabelled drug [2].

Yttrium-90 The radiometal ${ }^{90} \mathrm{Y}$ is a pure $\beta$-emitting isotope with a physical half-life of $64 \mathrm{~h}$. The maximum and mean $\beta$-particle energies are $2.28 \mathrm{MeV}$ and $0.934 \mathrm{MeV}$, respectively. The maximum and mean $\beta$ particle penetration depths in soft tissue are $11 \mathrm{~mm}$ and $3.9 \mathrm{~mm}$, respectively.

Lutetium-177 $\quad{ }^{177} \mathrm{Lu}$ is a $\beta$ - and $\gamma$-emitting radionuclide with a physical half-life of $162 \mathrm{~h}(6.73$ days). Compared to ${ }^{90} \mathrm{Y},{ }^{177} \mathrm{Lu}$ has lower maximum and mean $\beta$-particle energies (0.498 MeV and $0.133 \mathrm{MeV}$, respectively). These translate to maximum and mean soft-tissue penetration depths of $1.7 \mathrm{~mm}$ and $0.23 \mathrm{~mm}$, respectively. ${ }^{177} \mathrm{Lu}$ has two main gamma emission lines: $113 \mathrm{keV}(6 \%$ relative abundance) and $208 \mathrm{keV}(11 \%$ relative abundance). The latter properties of ${ }^{177} \mathrm{Lu}$ allow posttreatment imaging and dosimetry assessments.

DOTATOC DOTATOC is a derivatized somatostatin analogue peptide. DOTATOC is the abbreviated form of [DOTA0,Tyr3]octreotide, where DOTA stands for the bifunctional chelating molecule $1,4,7,10$ tetraazacyclo-dodecane-1,4,7,10tetraacetic acid, and Tyr3-octreotide is the modified octreotide. This peptide shows a high affinity for sstr2 $\left(\mathrm{IC}_{50} 14 \pm 2.6 \mathrm{nM}\right)$, but lower affinities for $\operatorname{sstr} 5\left(\mathrm{IC}_{50} 393 \pm 84\right.$ $\mathrm{nM})$ and sstr3 $\left(\mathrm{IC}_{50} 880 \pm 324 \mathrm{nM}\right)$ [3].

DOTATATE DOTATATE is also a derivatized somatostatin analogue peptide. DOTATATE is the abbreviated form of [DOTA0,Tyr3,Thr8]-octreotide or [DOTA0,Tyr3]-octreotate, and DOTA stands for the bifunctional metalchelating molecule. This peptide shows a six- to ninefold higher affinity for sstr2 $\left(\mathrm{IC}_{50} 1.5 \pm 0.4 \mathrm{nM}\right)$ than DOTATOC, but has no affinity for either sstr5 $\left(\mathrm{IC}_{50} 547 \pm 160 \mathrm{nM}\right)$ or sstr3 $\left(\mathrm{IC}_{50}>1,000 \mathrm{nM}\right)$ [4].

\section{Background}

NETs have proven to be ideal neoplasms for PRRNT, as the majority of these slow-growing malignancies overexpress sstrs. Appropriate candidates for PRRNT are patients presenting with well-differentiated or moderately differentiated neuroendocrine carcinomas, defined as NETs of grade 1 or 2 according to the WHO classification of 2010 [5]. The incidence of NETs has been rising over the past 30 years, particularly those arising from the midgut and pancreas [6]. The incidence of NETs in the USA rose from 10.9 to 52.4 per million between 1973 and 2004 (SEER database). NETs can occur in children and young adults, being diagnosed as early as at the age of 5 years, while their incidence increases with age. The clinical presentation may vary depending on the site of tumour origin. About $72 \%$ of NETs arise in gastrointestinal structures, $25 \%$ are bronchopulmonary in origin, and less than $5 \%$ arise at other sites (e.g. thymus, breast and genitourinary system). Frequently, these tumours are discovered when metastatic or locally advanced and therefore inoperable. NETs can be either functioning or nonfunctioning in nature. Functioning tumours are associated with clinical syndromes, such as the carcinoid syndrome (due to the release of serotonin). Other secreting tumours include insulinomas (inducing hypoglycaemia), gastrinomas (inducing Zollinger-Ellison syndrome), VIPomas (associated with the watery diarrhoea, hypokalaemia and achlorhydria syndrome; WDHA syndrome).

Anatomical imaging of NETs should be as detailed and extensive as possible to provide accurate information about site and extent of the primary tumour, and the location and extent of regional and distant metastases. An exact assessment of liver metastases and degree of liver involvement using ultrasonography, CT or MRI is central for accurate staging and for assessing the response to treatment [7].

Functional imaging procedures applying sstr imaging using ${ }^{111}$ In-pentetreotide (OctreoScan) with SPECT or PET with ${ }^{68} \mathrm{Ga}$-labelled SSA, combined with morphological imaging procedures, are used to collect essential information for staging, assessing sstr status and making decisions on the most appropriate therapy regimens $[8$, 9]. Serial morphological examinations are mandatory to monitor therapy and detect recurrent disease. Emerging data indicate that ${ }^{18} \mathrm{~F}$-FDG PET may have additional prognostic value [10]. This information, however, needs validation in larger studies.

Multiple treatment approaches are now available for patients presenting with metastatic disease, considering recently introduced molecular targeted therapies and multimodality treatment options. For the choice of the most appropriate treatment, information regarding anatomical location and local invasion of adjacent structures, tumour functionality, sstr status, histological grading and staging are required to facilitate the decision-making process within the multidisciplinary tumour board. If the disease is restricted to the liver, surgical and locoregional approaches should be considered primarily. Chemotherapy is appropriate for highly proliferating NETs and pancreatic NETs, keeping in mind the fact that the vast majority of NETs are rather insensitive to this treatment. 


\section{Treatment options in NETs}

Patients with NETs may present with local tumours, with or without regional or distant metastases. The common site of metastasis is the liver. These tumours may remain clinically silent until a significant liver tumour burden is present. Therapeutic options include surgery, SSA, interferon, chemotherapy, molecularly targeted agents, locoregional therapies and PRRNT. Supportive palliative care and pain control also play an important role in patient management. These options are not mutually exclusive and, for the most part, are interchangeable. Options of care, including PRRNT, should be chosen and implemented in a correct sequence by an experienced multidisciplinary team. This approach should provide the highest benefit while minimizing the risks and side effects and ensuring the best quality of life achievable for the patient. Surgery with curative intent should always be performed whenever feasible; in selected cases, and within a multidisciplinary approach, PRRNT may be beneficial as a neoadjuvant therapy to render a patient accessible to surgery. For functionally active tumours, cytoreductive strategies, e.g. transarterial chemoembolization (TACE), transarterial embolization (TAE), radiofrequency ablation (RFA) and other techniques such as selective internal radiation therapy (SIRT), should always be considered with the intention of ameliorating clinical symptoms. The optimal management of NETs is early surgical removal prior to the development of regional or distant metastases. Unfortunately, many patients are diagnosed with metastatic disease, when complete eradication of their tumours will not be possible. Removal of the primary tumour is indicated to prevent complications such as bleeding or small-bowel obstruction. Even in the presence of liver metastases, removal of the primary tumour has several advantages and seems to have a positive prognostic impact on survival [11-14]. Solitary or isolated liver metastases can be surgically removed, while a more diffuse liver infiltration is usually treated using a locoregional approach.

Locoregional approaches or local ablative therapies target predominantly liver metastases aiming at achieving local tumour control and alleviating functional secretory syndromes. Different techniques are applied depending on individual findings (number size and distribution of liver lesions, their morphology, focal or diffuse, and their vascularization), functional activity of the NET and locally available expertise. In an individual with few liver lesions with a preferably resected primary lesion, liver lesions can be treated by surgical resection with or without RFA or laserinduced interstitial thermoablation. In those with multifocal or diffuse liver disease causing a high tumour load, TACE and TAE are the preferred choices $[15,16]$. Local embolization techniques are particularly useful when treating patients with functionally active liver metastases. Following
TACE, symptomatic response rates of 60-95\% and biochemical response rates of 50-90\% are achieved and radiological response of 33-80\% have been reported [17-19]. Response duration is between 18 and 24 months. Similar response rates are achieved with TAE alone [16]. In general, the procedure may require more than one treatment session to ensure effectiveness and consolidation of the treatment and to minimize the risk of complications.

The recently introduced SIRT has shown variable response rates among individual centres [20]. Prospective studies are however lacking. In a single prospective study in 34 patients the objective response rate was $50 \%$ [19]. Given the lack of comparative studies of the different techniques used for local ablative and locoregional therapies, the choice of technique will be highly dependent on the physicians' experience in the different centres and on individual criteria such as number, size, vascularization and distribution of the lesions.

Among the medical treatments, octreotide and lanreotide are the two most used sstr agonists. They play an essential role in the control of both symptomatic and asymptomatic NETs and should be regarded as first-line therapy. SSA can be used with virtually all of the other therapeutic options available. As the vast majority (87-92\%) of NETs express sstr2, patients should always be offered this therapy alongside other concurrent therapeutic options, and for supportive care. Long-acting SSA possess secretory inhibiting action, and are approved for alleviating the symptoms of the carcinoid syndrome, such as flushing and diarrhoea or bronchial obstruction, and to prevent carcinoid crisis. It is reported that treatment with SSA may control the clinical syndrome in 40-90\% of patients subject to tumour load and dosage $[21,22]$. Nevertheless, patients may become refractory to syndrome control, and need incremental dosage increases of SSA. However, most patients with tumour progression require an additional treatment, including the use of PRRNT. The recent PROMID study conducted in Germany showed the effectiveness of long-acting SSA as an antiproliferative therapeutic agent in midgut NET. In this study, time to tumour progression in patients given octreotide LAR $30 \mathrm{mg}$ intramuscularly monthly was more than double that in patients receiving only placebo (6.0 vs. 14.3 months). The NCCN guidelines and very recently the ENETS guidelines have added octreotide as an option for antiproliferative treatment [23, 24].

Interferon-alpha (IFN- $\alpha$ ) has been used for treating patients with NETs, especially those with the carcinoid syndrome, for more than 25 years. It is considered the main antisecretory drug used for the treatment of functional tumours [25]. IFN- $\alpha$ effectively reduces hypersecretionrelated symptoms in patients with carcinoid syndrome in a similar manner to SSA. Partial tumour growth responses are also observed in 10-15\% of patients with malignant 
carcinoids, and stabilization in $39 \%$. IFN- $\alpha$ has also been demonstrated to be effective in endocrine pancreatic tumours [26]. The very common side effect of IFN- $\alpha$, namely a 'flu-like syndrome, limits both the use of high dosages and the duration of treatment due to intolerance forcing its interruption. Systemic chemotherapy is effective in some patients, especially those with poorly differentiated NET/neuroendocrine carcinoma (grade 3, WHO 2010) or progressive NET of the pancreas. However, in welldifferentiated midgut NETs/NETs (grade 1/2, WHO 2010) the response rates to chemotherapy are low (7-20\%) and a survival advantage has not been demonstrated [27, 28]. The standard treatment for neuroendocrine carcinoma (grade 3) is cisplatin and etoposide. The response rate with this combination is $42-67 \%$, and its duration is often short, ranging from 8 to 9 months [32]. The combination of irinotecan and cisplatin [29] or FOLFOX chemotherapy (5-fluorouracil or capecitabine and oxaliplatin) may be an alternative [30]. PRRNT is very rarely a suitable treatment option for neuroendocrine carcinoma (grade 3), because of the low expression of sstr but it may be considered following the failure of chemotherapy and if ${ }^{111}$ In-pentetreotide (OctreoScan) or ${ }^{68}$ Ga-DOTATOC/DOTATATE PET/CT demonstrates moderate to high sstr expression.

Systemic chemotherapy based on streptozotocin (Zanosar, STZ) is considered a standard therapy for progressive pancreatic NETs with low or moderate proliferative capacity. Combinations of STZ and 5-fluorouracil and/or doxorubicin have been shown to lead to partial remission rates of 35-40\% [31-33]. Recent phase II studies have shown efficacy of temozolomide based chemotherapy either with antiangiogenic drugs or capecitabine $[34,35]$. Standards of care for the use of chemotherapy have been defined by ENETS [36]. In recent years, the efficacy of molecular targeted therapies for treating NETs has been assessed in clinical trials. These therapies include angiogenesis inhibitors, single or multiple tyrosine kinase inhibitors and the novel SSA analogue pasireotide, for which clinical trials are ongoing. The drugs with the highest evidence of efficacy are sunitinib and everolimus (RAD-001). Both lead to extension of progression-free survival (PFS) of patients with advanced pancreatic NET. For everolimus, an mTOR inhibitor, there is evidence of efficacy in controlling NET arising from other sites associated with the carcinoid syndrome [37]. The most developed antiangiogenic drugs are sunitinib and the antiVEGF antibody bevacizumab. In a phase II study bevacizumab in combination with octreotide LAR led to partial tumour remission in $18 \%$ of patients and stable disease in $77 \%$ [38]. A recent international phase III study of sunitinib versus placebo in patients with progressive welldifferentiated endocrine pancreatic tumour was interrupted prematurely due to the striking superiority of sunitinib evident by a PFS of 11.1 vs. 5.5 months [39]. The objective remission rate was less than $10 \%$. The drug was recently approved by the US FDA and the European Medicines Agency for the treatment of advanced and progressive well-differentiated pancreatic NETs.

Everolimus has been studied in more than 1,000 patients with NET and has been included in several clinical trials (RADIANT-1, RADIANT-2, RADIANT-3 trials, RAMSETE trial). Antitumour activity of everolimus has been confirmed in RADIANT-1 in patients with progressive metastatic pancreatic NETs after failure of at least one line of cytotoxic chemotherapy. The trial studied 160 patients divided into two groups with or without monthly intramuscular octreotide acetate therapy. The combination therapy group showed significantly longer PFS (16.7 vs. 9.7 months) [40]. The efficacy of everolimus has been confirmed in a large international placebo-controlled trial including 410 patients with progressive pancreatic NET (RADIANT-3) [41]. Everolimus significantly reduced the risk of disease progression and led to a prolongation of PFS by 6.4 months (11 vs. 4.6 months) compared to placebo. Objective tumour response was low (4.8\% partial remissions). Disease control rate (partial response + stable disease) was, however, higher with everolimus than with placebo with best supportive care $(77.7 \%$ vs. $52.7 \%)$. Side effects were rarely grade 3 or 4 ; the most frequently reported side effects included stomatitis, anaemia and hyperglycaemia. In May 2011 the US FDA approved everolimus for the treatment of progressive NETs of pancreatic origin in patients with nonresectable, locally advanced, or metastatic disease.

In the global supportive approach to the patient, and when delivering PRRNT, nutrition and pain control are an essential component of care. Treatment of pain in patients with NET follows the general principles followed in adult and paediatric oncology [42]. Effective treatment of NETs, such as PRRNT, may alleviate pain, including bone pain. Treatment of painful bone metastasis is also mandatory with the administration of bisphosphonates as supportive therapy.

\section{PRRNT a historical overview}

PRRNT using radiolabelled octreotide was first attempted in the 1990s. The initial phase I trial investigated the safety and efficacy of using high activities of the diagnostic compound ${ }^{111}$ In-octreotide as a therapeutic radiopharmaceutical. The results in terms of clinical efficacy were attributed to the effect of intracellular emission of the Auger and conversion electrons by ${ }^{111}$ In following the internalization of the peptidereceptor complex. Partial remissions were exceptional, and furthermore three patients developed leukaemia or myelodysplastic syndrome from the group receiving the highest cumulative dose (90-100 GBq) [43]. In Europe, ${ }^{111}$ In-pentetreotide was abandoned as a therapy option in favour of the more efficient $\beta$ emitters ${ }^{90} \mathrm{Y}$ and ${ }^{177} \mathrm{Lu} .{ }^{111}$ In-pentetreotide is, 
however, still used by some in the USA mainly due to the lack of availability of $\beta$-emitting radiotracers. High-energy $\beta$ emitters, such as ${ }^{90} \mathrm{Y}$ with a longer $\beta$ range in soft tissue, were considered more promising for the treatment of bulky tumour. A novel analogue, $\mathrm{Tyr}^{3}$-octreotide, with a similar affinity profile for sstrs, was developed. Linked to a macrocyclic chelator (DOTA), it allows simple and stable radiolabelling of ${ }^{111} \mathrm{In}$ and ${ }^{90} \mathrm{Y}$ to $\left[\mathrm{DOTA}^{0}, \mathrm{Tyr}^{3}\right]$-octreotide $\left({ }^{90} \mathrm{Y}\right.$-DOTATOC) [44]. PRRNT using ${ }^{90}$ Y-DOTATOC was first used in 1996 in a patient in Basel, Switzerland. The excellent subjective and objective response following several cycles of ${ }^{90} \mathrm{Y}$ DOTATOC led to high expectations as to the therapeutic potential of PRRNT in patients with NET. Since then other centres worldwide have conducted clinical trials with ${ }^{90} \mathrm{Y}$ DOTATOC [45]. Since the year 2000, octreotate $\left(\mathrm{Tyr}^{3}, \mathrm{Thr}^{8}\right.$ octreotide), a newer analogue with improved affinity for sstr2, has been synthesized. The chelated analogue $\left[\mathrm{DOTA}^{0}, \mathrm{Tyr}^{3}\right]$ octreotate (DOTATATE) can be labelled with the $\beta$ - and $\gamma$ emitting isotope ${ }^{177} \mathrm{Lu}$ and has been used in clinical studies.

\section{Indications and contraindications}

Indications

PRRNT is indicated for the treatment of patients with positive expression of sstr2, or metastatic or inoperable NET [46-50]. Candidate patients for PRRNT using radiolabelled somatostatin analogues are mainly those with sstr2-expressing NET of the gastroenteropancreatic and bronchial tracts, but may also include patients with phaeochromocytoma, paraganglioma, neuroblastoma [51] or medullary thyroid carcinoma [52-56]. The ideal candidates for PRRNT are those with well-differentiated and moderately differentiated neuroendocrine carcinomas defined as NET grade 1 or 2 according to the recent WHO 2010 classification [4].

\section{Contraindications}

\section{Absolute}

- Pregnancy.

- Severe acute concomitant illnesses.

- Severe unmanageable psychiatric disorder.

\section{Relative}

- Breast feeding (if not discontinued).

- Severely compromised renal function: for PRRNT with a ${ }^{90}$ Y-labelled peptide age-adjusted normal renal function is essential. Patients with compromised renal function may still be considered for ${ }^{177} \mathrm{Lu}$-labelled peptide treatment. For ${ }^{177}$ Lu-labelled peptide a mild to moderate grade of renal impairment can be tolerated (e.g. creatinine $\leq 1.7 \mathrm{mg} / \mathrm{dl})$. Glomerular filtration rate (GFR) and tubular extraction rate (TER) should be at least $60 \%$ of mean age-adjusted normal values.

- Severely compromised bone marrow: noncompromised haematological reserve should be present before PRRNT. Suggested reference values are:

WBC $<3,000 / \mu \mathrm{l}$, with absolute neutrophil count $<1,000 / \mu \mathrm{l}$ PLT $<75,000 / \mu$ l for ${ }^{177} \mathrm{Lu}$-DOTATATE, $<90,000 / \mu l$ for ${ }^{90} \mathrm{Y}$-DOTATOC, $\mathrm{RBC}<3,000,000 / \mu \mathrm{l}$.

\section{Special warnings}

Renal function

The kidney is the dose-limiting organ at the activities normally used for PRRNT. Side effects involving the kidney and the bone marrow are mild if adequate renal protection and fractionation are used. Renal function should be assessed by means of laboratory tests (creatinine and BUN), or calculation of creatinine clearance (e.g. Cockroft-Gault formula). Additional studies, e.g. measurement of GFR with 24-h urine collection or nuclear medicine methods (e.g. ${ }^{99 m}$ Tc-MAG3 with TER determination, ${ }^{99 \mathrm{~m}}$ Tc-DTPA GFR or effective renal plasma flow using hippuran), should be performed in patients with risk factors for renal toxicity or with compromised renal function, and in all children.

\section{Aggravating conditions (caveats)}

- Renal outflow obstruction, potentially leading to hydronephrosis, and, ultimately, to loss of renal function, should always be ruled out or otherwise corrected before PRRNT.

- Previous myelotoxic chemotherapy and extended external beam irradiation fields to the bone marrow (pelvis, spine), particularly if performed in the weeks preceding the PRRNT, do increase the risk of bone marrow failure after PRRNT. In doubtful cases of haematological compromise, a bone marrow biopsy might be indicated to assess bone marrow status in pretreated patients and to assess the risk when planning for multiple PRRNT cycles (e.g. intervals between cycles). Depending on the amount of ${ }^{90}$ Y-DOTATOC or ${ }^{177}$ Lu-DOTATATE activity injected, persisting depressed platelets values following prior PRRNT cycle(s) can impede the timing and dosing of subsequent cycles. 
- A patient with pending liver failure should be considered with caution before being submitted to PRRNT.

\section{Procedure}

\section{Pretherapy assessment}

The availability of the following information is mandatory when considering a patient for PRRNT:

- $\quad$ NET proven by histopathology (immunohistochemistry).

- High sstr expression determined by functional wholebody imaging with ${ }^{111}$ In-pentetreotide (OctreoScan) or ${ }^{68}$ Ga-DOTA-peptide PET/CT or immunohistochemistry.

The following criteria should be taken into consideration when deciding whether or not to perform PRRNT.

- Karnofsky/Lansky performance status above $60 \%$ or ECOG performance status less than 2.

- Tumour differentiation, preferably grade $1 / 2$.

- Tumour proliferation rate, preferably with a Ki-67/mitotic index $\leq 20 \%$. In addition, the rate of tumour growth, as determined by CT or MRI, could be considered. Note that, in general, less-differentiated tumours showing high proliferation rates are better candidates for chemotherapy.

\section{Facility and personnel}

PRRNT is still considered an investigational treatment and its implementation must comply with national legislation and local requirements, as well as with ethical principles regarding human studies. The decision to provide PRRNT should be taken within a multidisciplinary tumour board, including all the specialists involved in the care of patients with NET. The facility requirements will depend on national legislation on the therapeutic use of radioactive agents. If inpatient therapy is required by national legislation, the treatment should take place in an approved facility. The facility must have appropriate personnel, radiation safety equipment, and procedures for waste management and handling accidental contamination of the site or personnel.

${ }^{90}$ Y-DOTATOC or ${ }^{177}$ Lu-DOTATATE should be administered by appropriately trained medical staff with supporting nursing staff with a medical physics expert available. Physicians responsible for treating patients should have a general knowledge of the pathophysiology and natural history of the respective diseases, should be familiar with alternative forms of therapy, and should be able to closely liaise with other physicians involved in managing the patients. Clinicians involved in the utilization of unsealed radionuclide sources for therapy must also be knowledgeable about and compliant with applicable national legislation and local regulations.
Patient preparation

\section{Renal protection}

Together with the bone marrow, the kidneys are the critical organs in PRRNT particularly when using ${ }^{90}$ Y-DOTATOC. Proximal tubular reabsorption of the radiopeptide and subsequent retention in the interstitium result in excessive renal irradiation. Nephrotoxicity may be aggravated by risk factors, such as preexisting hypertension or diabetes mellitus [57]. To counteract and reduce the high kidney retention of radiopeptides, positively charged amino acids, such as L-lysine and/or L-arginine, are coinfused to competitively inhibit the proximal tubular reabsorption of the radiopeptide. The coadministration of these amino acids leads to a significant reduction in the renal absorbed dose, which ranges from $9 \%$ to $53 \%$ [58]. Renal absorbed dose is further reduced by up to $39 \%$ by extending the infusion time of the amino acid solution over $10 \mathrm{~h}$, and up to $65 \%$ by extending the protection over 2 days following radiopeptide administration, thereby covering the renal elimination phase more efficiently $[59,60]$.

\section{Amino acid protection protocols}

Lysine and/or arginine should be diluted appropriately in large volumes of normal saline in order to hydrate the patient, unless the patient suffers from cardiac insufficiency (e.g. carcinoid heart valve disease), in which case volume overload, possibly leading to acute exacerbation of the condition, should be avoided. Hyperosmotic solutions in particular should be avoided since they can induce dangerous electrolyte imbalances that might lead to severe metabolic acidosis and cardiac arrhythmias. An appropriate dilution is $25 \mathrm{~g}$ of amino acid in 11 of normal saline.

Before beginning the amino acid infusion, appropriate measures against nausea and vomiting should be undertaken by administering an antiemetic (e.g. 5-HT3 antagonist, such as granisetron) and/or a corticosteroid (e.g. dexamethasone). Antiemetic can be repeated if needed. Amino acid infusion should be started 30-60 $\mathrm{min}$ before administration of the radiopeptide and should be maintained over $4 \mathrm{~h}$. Particular attention and care should be given to avoiding possible electrolyte imbalance (hyperkalaemia and hypernatraemia), and the consequent metabolic acidosis, that might lead to mild nausea and vomiting [61]. These side effects should be managed by hydrating the patient with normal saline and possibly by repeating corticosteroid or antiemetic administrations.

\section{Proposed amino acid protective schemes}

\section{Single-day $50-\mathrm{g}$ protection protocol}

A solution containing a 50-g cocktail of lysine and arginine (25 g of lysine and $25 \mathrm{~g}$ of arginine) diluted in 21 of 
normal saline infused over $4 \mathrm{~h}$, starting 30-60 min before PRRNT.

\section{Three-day 25 -g protection protocol}

During day 1, a cocktail of $25 \mathrm{~g}$ of lysine diluted in 11 of normal saline is infused over $4 \mathrm{~h}$, starting 30-60 min before the PRRNT. This is followed by the administration of a $12.5 \mathrm{~g}$ lysine solution in $500 \mathrm{ml}$ of normal saline over $3 \mathrm{~h}$ twice a day on the second and third day after therapy. This protocol is aimed at maximizing renal protection while minimizing the side effects of the amino acid infusion.

\section{Three-day 50 -g protection protocol}

A 50-g solution of lysine and arginine $(25 \mathrm{~g} / 25 \mathrm{~g})$ diluted in 21 normal saline infused over $4 \mathrm{~h}$ during the first day starting 30-60 min before therapy. This is followed by the administration of an additional $12.5 \mathrm{~g}$ lysine diluted in $500 \mathrm{ml}$ of normal saline infused over $3 \mathrm{~h}$ twice a day on day 2 and day 3 after therapy.

\section{Single-day $50 \mathrm{~g}+$ Gelofusine}

Renal uptake of radiolabelled somatostatin analogues can in part be attributed to the receptor-mediated endocytic renal transporter system involving megalin-mediated cubilindependent endocytosis across the proximal epithelium. Gelofusine, a succinylated bovine gelatin molecule commonly used as a plasma expander, can be administered to further reduce kidney absorbed radiation dose (by about $45 \%)$ through its interaction with the megalin/cubilin receptor-mediated transporter system [62, 63]. There have been some safety concerns about the use of Gelofusine following the occurrence of allergic reactions, although mild in most cases. Severe anaphylactoid reactions are described in approximately $0.04 \%[64,65]$. The treating physician should be aware of these effects and be prepared to treat them accordingly with antihistaminic drugs, corticosteroids or epinephrine. A protection protocol consists of a cocktail of $25 \mathrm{~g}$ lysine $+25 \mathrm{~g}$ arginine diluted in 21 of normal saline infused over $4 \mathrm{~h}$ starting 30-60 min before therapy, and Gelofusine infusion as a bolus of $1 \mathrm{ml} / \mathrm{kg}$ body weight over $10 \mathrm{~min}$ before therapy, followed by Gelofusine infusion at $0.02 \mathrm{ml} / \mathrm{kg} / \mathrm{min}$ over $3 \mathrm{~h}$ after radiopeptide infusion. Due to reported adverse immunogenic reactions, vital parameters should be monitored during Gelofusine infusion [62].

Precautions in special clinical conditions In patients with severe cardiac insufficiency, volume overload that might lead to acute cardiac insufficiency and decompensation, should be avoided. Therefore, formulations with lower amounts of amino acids and hence lower volumes should be chosen (e.g. $25 \mathrm{~g}$ of lysine or arginine diluted in a maximum of 11 of normal saline). In any case, a stringent monitoring regimen with participation of a cardiologist is recommended. In patients with preexisting nephrolithiasis, forced diuresis might mobilize kidney stones leading to acute renal colic. These events should be treated appropriately but, if possible, anticipated and avoided by infusing lower volumes. Phlebitis associated with the hyperosmolarity of the infused amino acid solution may occur at the site of injection. This condition can be treated with local vasoprotective creams.

\section{Somatostatin analogue withdrawal}

Somatostatin analogues are available as short-acting or long-acting preparations. These should be discontinued prior to PRRNT as they might interfere with receptor targeting. The duration of interruption, however, depends on the halflife of the analogue used. Withdrawal periods of 4-6 weeks for long-acting release formulations and of at least $24 \mathrm{~h}$ for short-acting formulations are considered good clinical practice. This topic is still a matter of debate [7, 8]. In practice a long-acting release formulation is substituted by a shortacting formulation 1 month prior to PRRNT.

\section{Radiopharmaceutical and administration}

\section{Quality control}

Both ${ }^{90} \mathrm{Y}$ and ${ }^{177} \mathrm{Lu}$ are trivalent metals; they form a highly stable complex with the DOTA chelating molecule. "Simple" radiochemical purity (RP) testing to assess the fraction of free radionuclide using thin layer chromatography or solid phase extraction (using a Sep-Pak cartridge) is not mandatory for commercially acquired therapeutic radiopharmaceuticals. However, if such quality control is desired by the end-user, it should be conducted by adequately trained and qualified professionals. Applying this simple test, the RP should not fall below $98 \%$. It is worth noting that a more sophisticated method such as high-performance liquid chromatography might reveal additional impurities, and thus a RP of $98 \%$ will be difficult to achieve. As to the amount of peptide employed for an individual treatment cycle (single infusion), the consensus is that for formulations labelled with ${ }^{177} \mathrm{Lu}$ the mass of peptide should be between 100 and $200 \mu \mathrm{g}$, and should not exceed $250 \mu \mathrm{g}$ per patient dose, while for carrier-free ${ }^{90} \mathrm{Y}$ it should be between 100 and $150 \mu \mathrm{g}$ per patient. It is common practice to add excess sodium DTPA to the radiopharmaceutical prior to dispensing because it binds free radiometals and facilitates their fast renal clearance. The specific activity should not fall below a certain value. ${ }^{90} \mathrm{Y}$ is produced as a carrier-free radionuclide from the parent radioisotope ${ }^{90} \mathrm{Sr}$ with a theoretically maximum achievable specific activity close to $1,295 \mathrm{MBq} / \mu \mathrm{g}$ (35 mCi $/ \mu \mathrm{g})$. Metal impurities, particularly iron, lead to a significant lowering of the specific activity of the radiopeptide and can occasionally impede the labelling procedure. 
The radioisotope ${ }^{177} \mathrm{Lu}$ is produced by a nuclear reactor either via the direct or the indirect pathway; the direct pathway involves the n-gamma irradiation of an enriched ${ }^{176} \mathrm{Lu}$ target. The indirect pathway involves the irradiation ${ }^{176} \mathrm{Yb}$ to produce the short-lived ${ }^{177} \mathrm{Yb}$ $\left(T_{1 / 2} \quad 1.9 \mathrm{~h}\right)$ that decays to ${ }^{177} \mathrm{Lu}$. The latter method avoids the production of the long-lived ${ }^{177 \mathrm{~m}} \mathrm{Lu}\left(T_{1 / 2}\right.$ 60 days). Few high neutron-flux reactors are capable of producing ${ }^{177} \mathrm{Lu}$ of a specific activity in excess of $0.74 \mathrm{GBq} / \mu \mathrm{g}(20 \mathrm{Ci} / \mathrm{mg})$. By the time of radiolabelling the specific activity is around $0.555 \mathrm{GBq} / \mu \mathrm{g}(15 \mathrm{Ci} / \mathrm{mg})$; this, however, should not fall below $10 \mathrm{Ci} / \mathrm{mg}$. In practice, a specific activity of 37 to $74 \mathrm{MBq}(1-2 \mathrm{mCi})$ ${ }^{177} \mathrm{Lu}$ per microgram of precursor is routinely achieved and is accepted for clinical use [66].

\section{Administration}

During the administration of the radiopeptide, a physician must remain nearby. A resuscitation cart as well as a trained emergency team must be available. The radiopharmaceutical should be diluted with saline to a final volume ranging from $10 \mathrm{ml}$ to $100 \mathrm{ml}$, depending on the infusion system used. The radiopharmaceutical should be administered via an indwelling catheter to ensure safe intravenous administration and prevent paravascular infiltration, and should be administered over 10 to $30 \mathrm{~min}$, depending on the infusion system used. The radiopeptide may be coinfused with amino acid solution via a three-way stopcock ("piggy-back"). The line should be flushed with saline after completion of radiopeptide infusion. PRRNT may reproduce the syndromes of the respective functional tumours due to the sudden massive release of the hormones and stimulation of their corresponding receptors. The clinical manifestation is dependent on the specific hormone involved. The following measures are therefore recommended. Vital signs (at least blood pressure and pulse) should be monitored before and after therapy infusion in symptomatic patients. Therapeutic interventions should be undertaken to treat the functional syndrome effects or exacerbation (e.g. carcinoid syndrome/hypotension, hypoglycaemia, hypergastrinaemia, hypertension, hypotension, WDHA syndrome, electrolyte imbalance). Nursing personnel must be instructed in radiation safety. Any serious or life-threatening medical condition should be noted and contingency plans put in place in case radiation precautions need to be breached to allow emergency medical care. In a medical emergency, concerns about radiation exposure should not hinder the prompt delivery of appropriate medical care to the patient. During the first 2 days after PRRNT the high levels of activity excretion in the urine is of particular concern. Patients should be advised to observe rigorous hygiene to avoid contaminating persons using the same toilet facilities. A double toilet flush is recommended after urination. Patients should wash their hands after urination. If contaminated with urine, patients should wash their hands with abundant cold water without scrubbing. Once discharged, patients should be cautioned to avoid soiling underclothing or areas around toilet bowls for 1 week following PRRNT. Considerably contaminated clothing should be washed separately. Incontinent patients should be catheterized prior to PRRNT and the catheter should be kept for 2 days thereafter. Urine bags should be emptied frequently. Gloves and protective clothing should be worn by staff caring for catheterized patients (or providing any care involving close contact). Women of childbearing potential should use effective contraception while undergoing treatment and avoid pregnancy for at least 6 months thereafter. Male patients should consider sperm banking before therapy.

\section{Treatment regimens for the noncompromised patient}

${ }^{90}$ Y-DOTATATE $/{ }^{90}$ Y-DOTATOC

- Administered activity: $3.7 \mathrm{GBq}(100 \mathrm{mCi}) / \mathrm{m}^{2}$ body surface

- Number of cycles: two

- Time interval between cycles: 6-12 weeks or

- Administered activity: 2.78-4.44 GBq (75-120 mCi)

- Number of cycles: two to four

- Time interval between cycles: 6-12 weeks

${ }^{177}$ Lu-DOTATATE $/{ }^{177}$ Lu-DOTATOC

- Administered activity: 5.55-7.4 GBq (150-200 mCi)

- Number of cycles: three to five

- Time interval between cycles: 6-12 weeks

Combination ${ }^{90} \mathrm{Y}^{177} \mathrm{Lu}$ peptides Combination therapies with ${ }^{90} \mathrm{Y}$ and ${ }^{177} \mathrm{Lu}$ peptides are being actively investigated and may prove to be of additional therapeutic benefit. However, such combination treatments should be performed in centres with sufficient competence and extensive experience. In this case administered activities should be adjusted on an individual basis.

Sequential administration:

- ${ }^{90} \mathrm{Y}$ administered activity: $2.5-5.0 \mathrm{GBq}(68-135 \mathrm{mCi})$

- ${ }^{177} \mathrm{Lu}$ administered activity: 5.55-7.4 GBq (150$200 \mathrm{mCi}$ )

- Number of cycles: two to six

- Time interval between cycles: 6-16 weeks

Concurrent therapies, administering a cocktail of ${ }^{177} \mathrm{Lu}$ and ${ }^{90} \mathrm{Y}$ peptides are also emerging. 


\section{The compromised patient}

For the compromised patient, the administered activity may be reduced and treatment cycles are individualized with due consideration to prevailing clinical and biochemical parameters, and the results of dosimetric studies.

In patients with reduced renal function the following additional interventions are used:

(a) Nephrourology consultation.

(b) Extensive hydration (e.g. 2-3 1 of fluid intake, if clinically appropriate) prior to PRRNT.

(c) Diuretics (e.g. furosemide) should be considered in case of dilated renal pelvis and delayed outflow.

(d) Whenever possible, consider the patient for ${ }^{177} \mathrm{Lu}-$ based treatments.

In patients with reduced haematological values the following additional interventions are used:

(a) Haematologist consultation.

(b) When required, packed red blood cells or platelet concentrate support may be given following PRRNT.

(c) If needed, growth factor support with granulocyte stimulating factors or erythropoietin (or derivatives) can be considered not earlier than 10 days after PRRNT.

(d) In patients with severely compromised bone marrow reserves, peripheral stem cell harvesting as a precautionary measure could be considered before PRRNT and, if necessary, reinfusion could be performed after an appropriate time from PPRNT has elapsed.

\section{Special considerations for PRRNT in children}

NETs and neural crest tumours in children express high levels of sstrs and can potentially be treated with PRRNT. With the exception of appendiceal carcinoid, most NETs in children are metastatic at diagnosis. Children under the age of 18 years have been excluded from participation in PRRNT trials resulting in a lack of information on safety, toxicity and efficacy in this age group. Conservatively, absorbed doses to the kidney are limited to less than 2123 Gy. ${ }^{90}$ Y-DOTATOC has been used in children with administered activities of $1.5-1.85 \mathrm{GBq} / \mathrm{m}^{2}$ per cycle for up to three cycles [67]. With regard to the use of ${ }^{177} \mathrm{Lu}-$ DOTATATE in children, there is no widespread experience, and activities should be adapted per square metre [68].

\section{Retreatment options}

The decision to re-treat a patient with PRRNT should only be undertaken within the framework of the tumour board. In patients who have previously responded to PRRNT, retreatment may be considered in those with well-documented disease progression and taking into account the total previous radiation dose to the kidneys and bone marrow. This new PRRNT course will be subject to the same eligibility criteria applied to the first radiopeptide treatment cycle. The options include the use of the same or a different radiopeptide. For instance, choosing ${ }^{177}$ Lu-labelled peptides may be warranted, especially when considering the preservation of kidney function. When designing a retreatment regimen, due consideration should be given to the possibility of exceeding the renal threshold dose especially in patients with a good prognosis and expectation of long survival. Using ${ }^{177}$ Lu-labelled peptides, whole-body imaging should always be performed following each cycle to document the distribution of the radiopharmaceutical and to evaluate the functional response to PRRNT.

\section{Dosimetry}

Radiation dosimetry of normal organs and malignant lesions provides an insight for optimizing the delivery PRRNT, thereby allowing the dose delivered to the tumour to be maximized while minimizing the dose delivered to normal organs, particularly the kidney and bone marrow. If feasible, patient-specific dosimetry can provide valuable information to assess organ-specific radiation absorbed doses and to assess the risk of delayed organ toxicity, particularly of the kidneys and bone marrow in a patient with known risk factors (see Table 1).

Different dosimetry methods, practical and sophisticated, can be applied depending on final objective and availability of resources. Input data include data from blood, urine, and whole-body scans adequately scheduled up to at least 3 days after PRRNT. Planar images are useful to derive biokinetics over time, while SPECT and SPECT/CT fused images, although requiring more time to acquire, provide insight into organ-specific three-dimensional activity distribution. The MIRD scheme provides reference techniques for internal dosimetry. Dedicated software (OLINDA/EXM) has been used to derive mean absorbed dose estimates for ${ }^{177}$ Lu and ${ }^{90}$ Y peptides; [69, 70].

PRRNT dose estimates in organs are generally calculated using the MIRD scheme, with the basic formula:

$D=\widetilde{A} \times S=A_{0} \times \tau \times S$,

where $\tilde{A}$ is the integral activity in the organ, $A_{0}$ is the initial activity in the organ, $\tau$ is the residence time corresponding to the total number of decays occurring in the organ divided by $A_{0}$, and $S$ is a dose conversion factor depending on the properties of the radionuclide and the target. The value of $S$ should be corrected for the actual volume and mass of the organ. Once the integral activities in the organs of interest 
Table 1 Reported absorbed radiation dose estimates following PRRNT utilizing ${ }^{90}$ Y-DOTATOC and ${ }^{177} \mathrm{Lu}$-DOTATATE. Values are organ absorbed doses per unit activity $(\mathrm{Gy} / \mathrm{GBq})$; mean $\pm \mathrm{SD}$ or median (range)
${ }^{\mathrm{a}}$ Dosimetry performed using

${ }^{111}$ In-octreotide (OctreoScan). In all other investigations dosimetry was performed using either ${ }^{111}$ In-DOTATOC, ${ }^{86}$ Y-DOTATOC or ${ }^{177} \mathrm{Lu}-$ DOTATATE

\begin{tabular}{|c|c|c|c|c|}
\hline \multirow[t]{2}{*}{ Organ } & \multicolumn{2}{|l|}{${ }^{90}$ Y-DOTATOC } & \multicolumn{2}{|l|}{${ }^{177} \mathrm{Lu}$-DOTATATE } \\
\hline & Radiation dose & Reference & Radiation dose & Reference \\
\hline \multirow[t]{6}{*}{ Red marrow } & $0.03 \pm 0.01$ & {$[75,76]$} & $0.07 \pm 0.01$ & {$[85]$} \\
\hline & $0.17 \pm 0.02$ & [79] & $0.04(0.02-0.06)$ & {$[86]$} \\
\hline & $0.09(0.03-0.18)$ & {$[80]$} & $0.04 \pm 0.02$ & {$[65]$} \\
\hline & $0.05 \pm 0.00$ & {$[81]$} & $0.02 \pm 0.03$ & {$[74]$} \\
\hline & $0.06 \pm 0.02$ & {$[82]$} & & \\
\hline & $0.12 \pm 0.02$ & $\begin{array}{l}{[67]} \\
\quad\left(\text { paediatric, }{ }^{111} \mathrm{In}\right)^{\mathrm{a}}\end{array}$ & & \\
\hline \multirow[t]{8}{*}{ Kidneys } & $\begin{array}{l}6.05 \\
\text { (unprotected) }\end{array}$ & {$[83]$} & $\begin{array}{c}1.65 \pm 0.47 \text { (unprotected) } \\
0.88 \pm 0.19 \text { (protected) }\end{array}$ & {$[85]$} \\
\hline & $\begin{array}{l}3.7 \text { (1.9-7.6) left; } 4.3 \\
\text { (3.4-7.4) right }\end{array}$ & {$[84]$} & $0.62(0.45-17.74)$ & {$[86]$} \\
\hline & $3.84 \pm 2.02$ (unprotected) & {$[74,76]$} & $0.9 \pm 0.3$ & {$[65]$} \\
\hline & $2.84 \pm 0.64$ & {$[79]$} & $(0.32-1.67)$ & {$[87]$} \\
\hline & $2.44(1.12-4.5)$ & {$[80]$} & & \\
\hline & $2.73 \pm 1.41$ & {$[82]$} & & \\
\hline & $1.71 \pm 0.89(1.20-5.10)$ & [59] & & \\
\hline & $2.24 \pm 0.84(1.1-3.8)$ & {$[67]^{\mathrm{a}}$} & & \\
\hline \multirow[t]{7}{*}{ Liver } & $0.75 \pm 0.65$ & {$[74,76]$} & $0.18(0.05-0.34)$ & {$[86]$} \\
\hline & $0.92 \pm 0.35$ & [79] & $0.13-1.10$ & {$[87]$} \\
\hline & $0.86(0.34-1.93)$ & {$[80]$} & $0.21 \pm 0.08$ & {$[85]$} \\
\hline & $0.66 \pm 0.15$ & {$[81]$} & & \\
\hline & $0.72 \pm 0.40$ & {$[82]$} & & \\
\hline & 0.27 & [83] & & \\
\hline & $\begin{array}{l}1.5 \pm 1.2(0.3-3.0) ; 0.35 \\
\text { low burden, } 2.67 \text { high burden }\end{array}$ & {$[67]^{\mathrm{a}}$} & & \\
\hline
\end{tabular}

are determined using numerical or compartmental models [71, 72], absorbed doses are generally calculated using dedicated software programs that use as input the residence time $\tau$ or the number of decays (OLINDA/EXM, RADAR) [71, 72].

The typical kinetics of radiopeptides, namely very fast blood clearance and renal elimination, determine the information required to obtain the integral activities in organs and tumour, which includes a whole dataset of scintigraphic images and data from blood and urine samples. Once the rough data are analysed, the activity in normal and tumour tissues is converted into time-activity curves for the calculation of absorbed dose estimates. The residence time for the red marrow is calculated from the residence time for blood, with the assumption that nonspecific uptake of the radiolabel takes place in the bone marrow. Uniform activity distribution and equivalent clearance in red marrow and blood are assumed. Due to the small size of the radiopeptide, the specific activity in bone marrow can be considered equal to the specific activity in blood [73, 74]. Overall, the dose to the red marrow results from bone marrow self-irradiation and the contribution from the remainder of the body. Tumour absorbed doses can then be estimated by assuming the lesion is a sphere and assuming a uniform activity distribution $[75,76]$. For ${ }^{90}$ Y-DOTATOC, the lack of $\gamma$ emission by ${ }^{90} \mathrm{Y}$ makes direct dosimetry quite difficult.
Bremsstrahlung images are rather difficult to quantify, requiring the application of complex corrections. For this reason two alternative options are used in clinical practice: ${ }^{111}$ In and ${ }^{86} \mathrm{Y}$ simulations. Despite some drawbacks, the extrapolated absorbed doses are reasonably similar. For dosimetric purposes ${ }^{111}$ In-DOTATOC has been used in clinical practice as a surrogate for ${ }^{90}$ Y-DOTATOC because of its similar chemical and kinetic properties. An alternative but far more demanding solution is to use DOTATOC labelled with the positron emitter ${ }^{86} \mathrm{Y}$. PET with ${ }^{86} \mathrm{Y}$-DOTATOC offers improved spatial resolution and quantitative analysis. Nevertheless, the short time window for data collection (24-40 h), as a consequence of the physical half-life $(14.7 \mathrm{~h})$ of ${ }^{86} \mathrm{Y}$, the low positron abundance, the high production cost and the low availability, are a challenge to the routine utilization of this method. ${ }^{111}$ In-pentetreotide scintigraphy and PET with ${ }^{68} \mathrm{Ga}$ DOTATOC are not suitable for accurate dosimetric calculation, the former due to its different kinetic behaviour and receptor affinity profile and the latter due to the short physical half-life (68 min) of ${ }^{68} \mathrm{Ga}$. Recently, a PET-based method promising quantitative imaging of ${ }^{90} \mathrm{Y}$ distribution was described [76-78]. In the case of ${ }^{177}$ Lu-DOTATATE, the gamma photons emission allows both imaging and dosimetry of the same compound. Therefore dosimetry is usually performed 
during the first courses of therapy following the injection of

${ }^{177}$ Lu-DOTATATE.

\section{Side effects}

Acute

Side effects of PRRNT are usually mild, if necessary precautions are taken. Side effects may be acute, related to the administration of amino acids or to the radiopeptide itself, or chronic. The coinfusion of amino acids enlarges the safety margin for treating with higher activities enabling higher tumour radiation doses to be attained safely. Side effects such as nausea, headache and rarely vomiting due to metabolic acidosis induced by the amino acid coadministration do occur in the majority of patients $[59,88]$. Particular attention and care should be given to avoiding possible electrolyte imbalance (hyperkalaemia, hypernatraemia), and the subsequent metabolic acidosis, that might lead to mild nausea and vomiting. The latter side effects should be managed by hydrating the patient with normal saline and possibly by repeating corticosteroid or antiemetic administrations.

PRRNT may exacerbate the syndromes related to the respective functional tumours, due to the sudden massive release of the hormones and receptor stimulation. The clinical manifestation is dependent on the specific hormone involved. The following measures are therefore recommended. Vital signs (at least blood pressure and pulse) should be monitored before and after radiopeptide infusion, especially in symptomatic patients. Therapeutic interventions should be undertaken to treat the for functional syndrome effects or exacerbation (e.g. carcinoid syndrome/hypotension, hypoglycaemia, hypergastrinaemia, hypertension, hypotension, WDHA syndrome, electrolyte imbalance) [89]. In patients without or with minor metastatic liver involvement, no significant hepatic toxicity has been reported. However, in patients with massive liver metastases and impaired liver function, liver toxicity may occur, and this should be considered, along with preexisting conditions affecting the liver, when choosing the appropriate radioisotope and dosing. In such cases, ${ }^{177} \mathrm{Lu}$-labelled peptides should be used and the administered activity should be reduced accordingly. After treatment, patients should avoid pregnancy for at least 6 months. Due to a temporary impairment of fertility, related to a transient damage to Sertoli cells, male patients should consider sperm banking before therapy.

Delayed side effects

\section{Renal toxicity}

The kidneys are the dose-limiting organs at the activities normally reached with PRRNT. Proper kidney protection, as discussed, is currently mandatory. However, despite kidney protection, loss of kidney function can occur after PRRNT, with a creatinine clearance loss of about $3.8 \%$ per year for ${ }^{177} \mathrm{Lu}$-DOTATATE and $7.3 \%$ per year for ${ }^{90} \mathrm{Y}$-DOTATOC [90]. In a series of 1,109 patients treated with ${ }^{90} \mathrm{Y}$-DOTATOC, the incidence of grade 4 and 5 kidney toxicity was found to be $9.2 \%$ [50]. Delayed renal toxicity following ${ }^{90}$ Y-DOTATOC treatment was observed more frequently in patients with predisposing risk factors including longstanding and poorly controlled hypertension and diabetes mellitus [56].

\section{Bone marrow toxicity}

Severe (grade 3 and 4), mostly reversible, acute bone marrow toxicity is observed in less than $10-13 \%$ of treatment cycles with ${ }^{90}$ Y-DOTATOC, and in 2-3\% of cycles with ${ }^{177}$ Lu-DOTATATE. Nevertheless, sporadic cases of myelodysplastic syndrome or overt acute myelogenous leukaemia have been reported $[45,49,50]$.

\section{Endocrine systems}

Despite the presence of sstr in normal pituitary, thyroid and adrenal glands and Langerhans cells, no significant alteration in endocrine hormone function have been reported [91].

\section{Results}

PRRNT with the somatostatin analogues ${ }^{90}$ Y-DOTATOC and ${ }^{177}$ Lu-DOTATATE has been explored in NET for more than a decade. Present knowledge and clinical studies indicate that it is possible to deliver tumoricidal absorbed doses (e.g. $>200 \mathrm{~Gy}$ ) to neoplastic tumours expressing sst2 receptors, leading to partial or complete objective responses in up to $30 \%$ of patients. The best objective responses have been reported in gastroenteropancreatic NETs (with partial responses ranging from $9 \%$ to $29 \%$ and complete remission from $2 \%$ to $6 \%$ ), and similar rates have been achieved in thorax (lung) NETs and neuroectodermal tumours (phaeochromocytomas, paragangliomas). Less favourable results have been reported for thymic NETs, medullary thyroid carcinoma and dedifferentiated thyroid carcinomas. Encouraging results have also been reported for sstr-positive tumours including meningiomas, medulloblastomas and astrocytomas [45-55, 92, 93].

Survival analyses have shown that patients with high sstr tumour expression at study entry, treated with either ${ }^{177} \mathrm{Lu}-$ DOTATATE or ${ }^{90}$ Y-DOTATOC, show significantly higher objective responses that translate into significantly longer survival $[48,50]$. A favourable biochemical response was also shown to be predictive of improved overall survival in patients with medullary (calcitonin) and dedifferentiated 
iodide-negative thyroid cancer (thyroglobulin) undergoing ${ }^{90}$ Y-DOTATOC treatment $[52,54]$. Symptomatic response, particularly a durable improvement in diarrhoea after ${ }^{90} \mathrm{Y}-$ DOTATOC treatment, proved to have an impact on PFS [49]. Initial data indicate that combination treatments with the two isotopes ${ }^{90} \mathrm{Y}$ and ${ }^{177} \mathrm{Lu}$ linked either to DOTATOC or to DOTATATE administered in sequential treatment cycles or as a cocktail infusion for several cycles improve survival $[94,95]$. However, larger prospective randomized trials are needed to confirm these results. In children and young adults only one controlled clinical phase I trial of PRRNT has been conducted utilizing ${ }^{90} \mathrm{Y}$-DOTATOC at activity levels of $1.11,1.48$ and $1.85 \mathrm{GBq} / \mathrm{m}^{2}$ per cycle in three cycles at 6-week intervals [67]. Three patients showed a partial response, five a minor response, five stable disease and two progressive disease. Dosimetry results were similar to the dosimetry estimates in adults.

The evaluation of response to PRRNT includes the assessment of functional and morphological responses, biochemical and symptomatic responses, and quality of life. Response is assessed by morphological and functional imaging techniques. Posttherapeutic ${ }^{177}$ Lu-DOTATATE scans provide valuable information on the intensity of uptake and localization of the tracer, and thus can be used to assess the response to the prior therapy cycles. The time-line to assess response may vary according to clinical needs (aggressiveness and extent of disease), but usually the first follow-up examination is recommended after 3 months, and subsequent follow-up examinations should be performed after 3-6 months. The reader is also referred to the ENETS guidelines for a more detailed discussion of the standards of care in NET follow-up and documentation [96].

\section{Follow-up}

The assessment of renal function is of paramount importance, as the kidney, together with the bone marrow, is the critical organ in PRRNT. The follow-up should include the evaluation of serum creatinine levels and the determination of creatinine clearance. In patients with pre-existing risk factors for delayed renal toxicity (high-risk group), in particular long-standing and poorly controlled hypertension and diabetes mellitus, single kidney or previously documented renal insult, mainly nephrotoxic chemotherapy, more precise methods to assess renal function are recommended. These techniques may include GFR measurements by means of ${ }^{99 \mathrm{~m}} \mathrm{Tc}-\mathrm{DTPA},{ }^{51} \mathrm{Cr}$ EDTA or measurement of ${ }^{99 \mathrm{~m}} \mathrm{Tc}-\mathrm{MAG} 3$ clearance.

Between-cycle follow-up

A complete blood cell count should be performed every 24 weeks. A higher frequency can be adopted if clinically required. Renal and liver function tests should be available before confirming subsequent cycles. Following careful clinical assessment, patients with blood values lower than the limits indicated for the first PRRNT cycle should receive a lower activity and/or the interval to the following PRRNT cycle should be extended. In severe cases, interruption of PRRNT might be considered.

Intermediate and long-term follow-up

A complete blood cell count (including mean corpuscular volume), and renal and liver function tests should be performed every $8-12$ weeks for the first 12 months, and thereafter twice a year if clinically indicated. Evaluation of response to treatment includes consideration of the clinical, biochemical, morphological and PET/SPECT functional status, and wellbeing of the patient. Morphological response is determined by contrast-enhanced CT or MRI. Objective response can be determined using the WHO, SWOG and RECIST criteria [97-99]. For assessing morphological response, $\mathrm{CT}$ is the preferred imaging technique, but this does not rule out the use of MRI. In some patients, CT and MRI may provide complimentary information. In any case, the same imaging modality should be employed during the follow-up of the individual patient. Depending on the disease duration and on tumour biology, these examinations are repeated every 3-6 months, but may be extended up to once every 12 months in the long-term follow-up in patients with a durable response.

Functional imaging is a valuable instrument to assess the course of the disease, and it has been demonstrated to be able to predict morphological response. Combined functional and morphological imaging may in many cases better reflect the true behaviour of the tumour following PRRNT. Such imaging includes ${ }^{111}$ In-pentetreotide (OctreoScan) and, if available, PET/CT with ${ }^{68} \mathrm{Ga}$-DOTA peptides or metabolic monitoring with, for example, ${ }^{18} \mathrm{~F}$-DOPA. However, functional imaging is not yet accepted as a substitute for morphological imaging as a means to assess tumour response to a treatment.

\section{Disclaimer}

This guidance document is a compilation of recent published evidence on the use of PRRNT in NETs and the personal experience of leading experts in the field reflecting personal opinion based on unpublished data. It pays special attention to and emphasizes gastroenteropancreatic presentations. The guidance is not provided as an inflexible set of rules and is not intended, nor should it be used, to establish legal standards of care. For these reasons as well as those set out below, this guidance should not be used in litigation in 
which the clinical decisions of practitioners are being called into question.

The EANM and the IAEA have written and approved guidelines to promote the cost-effective use of high-quality nuclear medicine therapeutic procedures. These generic recommendations cannot be rigidly applied to all patients in all practice settings. The guidelines should not be deemed inclusive of all proper procedures or exclusive of other procedures reasonably directed to obtaining the same results. Advances in medicine occur at a rapid rate. The date of a guideline should always be considered in determining its current applicability.

\section{Further reading}

For additional reading, the book published by the Nuclear Medicine Section, IAEA, entitled "Practical guidance on peptide receptor radionuclide therapy (PRRNT) for neuroendocrine tumours" (Human Health Series no. 12) is available for download using the link http://www.iaea.org/Publications/

Acknowledgments We wish to thank Dr. M. Chinol and Dr. C. DeChristoforo for their invaluable advice. This document was compiled in close cooperation with the Radionuclide Therapy, Oncology, Dosimetry, and Radiopharmacy Committees of the EANM and is endorsed by the Society of Nuclear Medicine and Molecular Imaging of the USA (SNMMI) under the auspices and support of the IAEA.

Open Access This article is distributed under the terms of the Creative Commons Attribution License which permits any use, distribution, and reproduction in any medium, provided the original author(s) and the source are credited.

\section{References}

1. Patel YC. Somatostatin and its receptor family. Front Neuroendocrinol. 1999;20:157-98.

2. Waser B, Tamma ML, Cescato R, Maecke HR, Reubi JC. Highly efficient in vivo agonist-induced internalization of sst 2 receptors in somatostatin target tissues. J Nucl Med. 2009;50:936-41.

3. Reubi JC, Schär JC, Waser B, Wenger S, Heppeler A, Schmitt JS, et al. Affinity profiles for human somatostatin receptor subtypes SST1-SST5 of somatostatin radiotracers selected for scintigraphic and radiotherapeutic use. Eur J Nucl Med. 2000;27:273-82.

4. Maecke HR, Reubi JC. Somatostatin receptors as targets for nuclear medicine imaging and radionuclide treatment. J Nucl Med. 2011;52:841-4.

5. Rindi G. The ENETS guidelines: the new TNM classification system. Tumori. 2010;96:806-9.

6. Modlin IM, Oberg K, Chung DC, Jensen RT, de Herder WW, Thakker RV, et al. Gastroenteropancreatic neuroendocrine tumors. Lancet Oncol. 2008;9:61-72.

7. Sundin A, Vullierme MP, Kaltsas G, Plöckinger U; Mallorca Consensus Conference participants; European Neuroendocrine Tumor Society. ENETS Consensus Guidelines for the Standards of Care in Neuroendocrine Tumors: radiological examinations. Neuroendocrinology. 2009;90:167-83.
8. Bombardieri E, Ambrosini V, Aktolun C, Baum RP, BishofDelaloye A, Del Vecchio S, et al. Oncology Committee of the EANM. 111In-pentetreotide scintigraphy: procedure guidelines for tumour imaging. Eur $\mathrm{J}$ Nucl Med Mol Imaging. 2010;37:1441-8.

9. Virgolini I, Ambrosini V, Bomanji JB, Baum RP, Fanti S, Gabriel $\mathrm{M}$, et al. Procedure guidelines for PET/CT tumor imaging with 68Ga-DOTA-conjugated peptides: 68Ga-DOTA-TOC, 68GaDOTA-NOC, 68Ga-DOTA-TATE. Eur J Nucl Med Mol Imaging. 2010;37:2004-10.

10. Binderup T, Knigge U, Loft A, Federspiel B, Kjaer A. 18Ffluorodeoxyglucose positron emission tomography predicts survival of patients with neuroendocrine tumors. Clin Cancer Res. 2010;16:978-85.

11. Kerström G, Hellman P, Hessman O. Midgut carcinoid tumors: surgical treatment and prognosis. Best Pract Res Clin Gastroenterol. 2005;19:717-28.

12. Plöckinger U, Couvelard A, Falconi M, Sundin A, Salazar R, Christ E, et al. Consensus guidelines for the management of patients with digestive neuroendocrine tumors: well-differentiated tumor/carcinoma of the appendix and goblet cell carcinoma. Neuroendocrinology. 2008;87:20-30.

13. Ramage JK, Goretzki PE, Manfredi R, Komminoth P, Ferone D, Hyrdel R, et al. Consensus guidelines for the management of patients with digestive neuroendocrine tumors: well-differentiated colon and rectum tumor/carcinoma. Neuroendocrinology. 2008;87:31-9.

14. Givi B, Pommier SJ, Thompson AK, Diggs BS, Pommier RF. Operative resection of primary carcinoid neoplasms in patients with liver metastases yields significantly better survival. Surgery. 2006;140:891-7.

15. Steinmüller T, Kianmanesh R, Falconi M, Scarpa A, Taal B, Kwekkeboom DJ, et al. Consensus guidelines for the management of patients with liver metastases from digestive (neuro)endocrine tumors: foregut, midgut, hindgut, and unknown primary. Neuroendocrinology. 2008;87:47-62.

16. Vogl TJ, Naguib NN, Zangos S, Eichler K, Hedayati A, NourEldin NE. Liver metastases of neuroendocrine carcinomas: interventional treatment via transarterial embolization, chemoembolization and thermal ablation. Eur J Radiol. 2009;72:517-28.

17. Kamat PP, Gupta S, Ensor JE, Murthy R, Ahrar K, Madoff DC, et al. Hepatic arterial embolization and chemoembolization in the management of patients with large-volume liver metastases. Cardiovasc Intervent Radiol. 2008;31:299-307.

18. Ruszniewski P, Malka D. Hepatic arterial chemoembolization in the management of advanced digestive endocrine tumors. Digestion. 2000;62 Suppl 1:79-83.

19. King J, Quinn R, Glenn DM, Janssen J, Tong D, Liaw W, et al. Radioembolization with selective internal radiation microspheres for neuroendocrine liver metastases. Cancer. 2008;113:921-9.

20. Kennedy AS, Dezarn WA, McNeillie P, Coldwell D, Nutting C, Carter D, et al. Radioembolization for unresectable neuroendocrine hepatic metastases using resin 90Y-microspheres: early results in 148 patients. Am J Clin Oncol. 2008;31:271-9.

21. Ruszniewski P, Ish-Shalom S, Wymenga M, O’Toole D, Arnold R, Tomassetti P, et al. Rapid and sustained relief from the symptoms of carcinoid syndrome: results from an open 6-month study of the 28-day prolonged-release formulation of lanreotide. Neuroendocrinology. 2004;80:244-51.

22. Modlin IM, Pavel M, Kidd M, Gustafsson BI. Review article: somatostatin analogues in the treatment of gastroenteropancreatic neuroendocrine (carcinoid) tumors. Aliment Pharmacol Ther. 2010;31:169-88.

23. Eriksson B, Klöppel G, Krenning E, Ahlman H, Plöckinger U, Wiedenmann $\mathrm{B}$, et al. Consensus guidelines for the management of patients with digestive neuroendocrine tumors - well- 
differentiated jejunal-ileal tumor/carcinoma. Neuroendocrinology. 2008;87:8-19.

24. Rinke A, Müller HH, Schade-Brittinger C, Klose KJ, Barth P, Wied M, et al. Placebo-controlled, double-blind, prospective, randomized study on the effect of octreotide LAR in the control of tumor growth in patients with metastatic neuroendocrine midgut tumors: a report from the PROMID Study Group. J Clin Oncol. 2009;27:4656-63.

25. Öberg K. Interferon in the management of neuroendocrine GEP tumors. Digestion. 2000;62 Suppl 1:92-7.

26. Eriksson B, Öberg K. An update of the medical treatment of malignant endocrine pancreatic tumors. Acta Oncol. 1993;32:203-8.

27. Moertel CG, Kvols LK, O'Connell MJ, Rubin J. Treatment of neuroendocrine carcinomas with combined etoposide and cisplatin. Evidence of major therapeutic activity in the anaplastic variants of these neoplasms. Cancer. 1991;68:227-32.

28. Moertel CG, Johnson CM, McKusick MA, Martin Jr JK, Nagorney DM, Kvols LK, et al. The management of patients with advanced carcinoid tumors and islet cell carcinomas. Ann Intern Med. 1994;120:302-9.

29. Mani MA, Shroff RT, Jacobs C, Wolff RA, Ajani JA, Yao JC, et al. A phase II study of irinotecan and cisplatin for metastatic or unresectable high grade neuroendocrine carcinoma [abstract]. J Clin Oncol 2008;26 Suppl; abstr 15550

30. Bajetta E, Catena L, Procopio G, De Dosso S, Bichisao E, Ferrari L, et al. Are capecitabine and oxaliplatin (XELOX) suitable treatments for progressing low-grade and high-grade neuroendocrine tumors? Cancer Chemother Pharmacol. 2007;59:637-42.

31. Kouvaraki MA, Ajani JA, Hoff P, Wolff R, Evans DB, Lozano R, et al. Fluorouracil, doxorubicin, and streptozocin in the treatment of patients with locally advanced and metastatic pancreatic endocrine carcinomas. J Clin Oncol. 2004;22:4762-71. Erratum in: J Clin Oncol. 2005;23:248.

32. Fjallskog ML, Janson ET, Falkmer UG, Vatn MH, Oberg KE, Eriksson BK. Treatment with combined streptozotocin and liposomal doxorubicin in metastatic endocrine pancreatic tumors. Neuroendocrinology. 2008;88:53-8.

33. Moertel CG, Lefkopoulo M, Lipsitz S, Hahn RG, Klaassen D. Streptozocin-doxorubicin, streptozocin-fluorouracil or chlorozotocin in the treatment of advanced islet-cell carcinoma. N Engl $\mathrm{J}$ Med. 1992;326:519-23.

34. Strosberg JR, Fine RL, Choi J, Nasir A, Coppola D, Chen DT, et al. First-line chemotherapy with capecitabine and temozolomide in patients with metastatic pancreatic endocrine carcinomas. Cancer. 2011;117:268-75.

35. Kulke MH, Stuart K, Enzinger PC, Ryan DP, Clark JW, Muzikansky A, et al. Phase II study of temozolomide and thalidomide in patients with metastatic neuroendocrine tumors. J Clin Oncol. 2006;24:401-6.

36. Eriksson B, Annibale B, Bajetta E, Mitry E, Pavel M, Platania M, et al. ENETS Consensus Guidelines for the Standards of Care in Neuroendocrine Tumors: chemotherapy in patients with neuroendocrine tumors. Neuroendocrinology. 2009;90:214-9.

37. Pavel M, Hainsworth JD, Baudin E, et al. A randomized, doubleblind, placebo-controlled, multicenter phase III trial of everolimus plus octreotide LAR vs placebo plus octreotide LAR in patients with advanced neuroendocrine tumors (NET) (RADIANT-2). Ann Oncol. 2010;21 Suppl 8:viii4.

38. Yao JC, Phan A, Hoff PM, Chen HX, Charnsangavej C, Yeung SC, et al. Targeting vascular endothelial growth factor in advanced carcinoid tumor: a random assignment phase II study of depot octreotide with bevacizumab and pegylated interferon alpha-2b. J Clin Oncol. 2008;26:1316-23.

39. Raymond E, Dahan L, Raoul JL, Bang YJ, Borbath I, LombardBohas C, et al. Sunitinib malate for the treatment of pancreatic neuroendocrine tumors. N Engl J Med. 2011;364:501-13. Erratum in: N Engl J Med. 2011;364:1082.

40. Yao JC, Lombard-Bohas C, Baudin E, Kvols LK, Rougier P, Ruszniewski P, et al. Daily oral everolimus activity in patients with metastatic pancreatic neuroendocrine tumors after failure of cytotoxic chemotherapy: a phase II trial. J Clin Oncol. 2010;28:69-76.

41. Yao JC, Shah MH, Ito T, Bohas CL, Wolin EM, Van Cutsem E, et al. Everolimus for advanced pancreatic neuroendocrine tumors. N Engl J Med. 2011;364:514-23.

42. Patrick DL, Ferketich SL, Frame PS, Harris JJ, Hendricks CB, Levin B, et al. National Institutes of Health State-of-the-Science Panel. National Institutes of Health State-of-the-Science Conference Statement: Symptom Management in Cancer: Pain, Depression, and Fatigue, July 15-17, 2002. J Natl Cancer Inst. 2003;95:1110-7.

43. Valkema R, De Jong M, Bakker WH, Breeman WA, Kooij PP, Lugtenburg PJ, et al. Phase I study of peptide receptor radionuclide therapy with [In-DTPA]-octreotide: the Rotterdam experience. Semin Nucl Med. 2002;32:110-22.

44. De Jong M, Bakker WH, Breeman WA, Bernard BF, Hofland LJ, Visser TJ, et al. Pre-clinical comparison of [DTPA0] octreotide, [DTPA0,Tyr3] octreotide and [DOTA0,Tyr3] octreotide as carriers for somatostatin receptor-targeted scintigraphy and radionuclide therapy. Int J Cancer. 1998; 75:406-11.

45. Kwekkeboom DJ, Mueller-Brand J, Paganelli G, Anthony LB, Pauwels S, Kvols LK, et al. Overview of results of peptide receptor radionuclide therapy with 3 radiolabeled somatostatin analogs. J Nucl Med. 2005;46 Suppl 1:62S-6S.

46. Kwekkeboom DJ, Kam BL, van Essen M, Teunissen JJ, van Eijck $\mathrm{CH}$, Valkema R, et al. Somatostatin receptor-based imaging and therapy of gastroenteropancreatic neuroendocrine tumors. Endocr Relat Cancer. 2010;17:R53-73.

47. Bodei L, Ferone D, Grana CM, Cremonesi M, Signore A, Dierckx RA, et al. Peptide receptor therapies in neuroendocrine tumors. J Endocrinol Invest. 2009;32:360-9.

48. Kwekkeboom DJ, de Herder WW, Kam BL, van Eijck CH, van Essen M, Kooij PP, et al. Treatment with the radiolabeled somatostatin analog [177Lu-DOTA0,Tyr3]octreotate: toxicity, efficacy, and survival. J Clin Oncol. 2008;26:2124-30.

49. Bushnell Jr DL, O’Dorisio TM, O’Dorisio MS, Menda Y, Hicks RJ, Van Cutsem E, et al. 90Y-Edotreotide for metastatic carcinoid refractory to octreotide. J Clin Oncol. 2010;28:1652-9.

50. Imhof A, Brunner P, Marincek N, Briel M, Schindler C, Rasch H, et al. Response, survival, and long-term toxicity after therapy with the radiolabeled somatostatin analogue [90Y-DOTA]-TOC in metastasized neuroendocrine cancers. J Clin Oncol. 2011;29:241623.

51. Gains JE, Bomanji JB, Fersht NL, Sullivan T, D'Souza D, Sullivan $\mathrm{KP}$, et al. 177Lu-DOTATATE molecular radiotherapy for childhood neuroblastoma. J Nucl Med. 2011;52:1041-7.

52. Bartolomei M, Bodei L, De Cicco C, Grana CM, Cremonesi M, Botteri E, et al. Peptide receptor radionuclide therapy with (90)YDOTATOC in recurrent meningioma. Eur J Nucl Med Mol Imaging. 2009;36:1407-16.

53. Iten F, Müller B, Schindler C, Rochlitz C, Oertli D, Mäcke HR, et al. Response to [90Yttrium-DOTA]-TOC treatment is associated with long-term survival benefit in metastasized medullary thyroid cancer: a phase II clinical trial. Clin Cancer Res. 2007;13:6696702.

54. Bodei L, Handkiewicz-Junak D, Grana C, Mazzetta C, Rocca P, Bartolomei M, et al. Receptor radionuclide therapy with $90 \mathrm{Y}-$ DOTATOC in patients with medullary thyroid carcinomas. Cancer Biother Radiopharm. 2004;19:65-71.

55. Iten F, Muller B, Schindler C, Rasch H, Rochlitz C, Oertli D, et al. [(90)Yttrium-DOTA]-TOC response is associated with survival 
benefit in iodine-refractory thyroid cancer: long-term results of a phase 2 clinical trial. Cancer. 2009;115:2052-62.

56. Teunissen JJ, Kwekkeboom DJ, Kooij PP, Bakker WH, Krenning EP. Peptide receptor radionuclide therapy for non-radioiodine-avid differentiated thyroid carcinoma. J Nucl Med. 2005;46 Suppl $1: 107 \mathrm{~S}-14 \mathrm{~S}$.

57. Bodei L, Cremonesi M, Ferrari M, Pacifici M, Grana CM, Bartolomei $\mathrm{M}$, et al. Long-term evaluation of renal toxicity after peptide receptor radionuclide therapy with 90Y-DOTATOC and 177Lu-DOTATATE: the role of associated risk factors. Eur J Nucl Med Mol Imaging. 2008;35:1847-56.

58. de Jong M, Krenning EP. New advances in peptide receptor radionuclide therapy. J Nucl Med. 2002;43:617-20.

59. Jamar F, Barone R, Mathieu I, Walrand S, Labar D, Carlier P, et al. (86YDOTA0)-DPhe1-Tyr3-octreotide (SMT487) - a phase 1 clinical study: pharmacokinetics, biodistribution and renal protective effect of different regimens of amino acid co-infusion. Eur J Nucl Med Mol Imaging. 2003;30:510-8.

60. Bodei L, Cremonesi M, Grana C, Rocca P, Bartolomei M, Chinol $\mathrm{M}$, et al. Receptor radionuclide therapy with 90Y-[DOTA]0-Tyr3octreotide (90Y-DOTATOC) in neuroendocrine tumors. Eur J Nucl Med Mol Imaging. 2004;31:1038-46.

61. Giovacchini G, Nicolas G, Freidank H, Mindt TL, Forrer F. Effect of amino acid infusion on potassium serum levels in neuroendocrine tumour patients treated with targeted radiopeptide therapy. Eur J Nucl Med Mol Imaging. 2011;38:1675-82.

62. Watkins J. Reactions to gelatin plasma expanders. Lancet. 1994;344:328-9.

63. Rolleman EJ, Melis M, Valkema R, Boerman OC, Krenning EP, de Jong $\mathrm{M}$. Kidney protection during peptide receptor radionuclide therapy with somatostatin analogues. Eur J Nucl Med Mol Imaging. 2010;37:1018-31.

64. Barron ME, Wilkes MM, Navickis RJ. A systematic review of the comparative safety of colloids. Arch Surg. 2004;139:552-63.

65. Wehrmann C, Senftleben S, Zachert C, Müller D, Baum RP. Results of individual patient dosimetry in peptide receptor radionuclide therapy with $177 \mathrm{Lu}$ DOTA-TATE and 177Lu DOTANOC. Cancer Biother Radiopharm. 2007;22:406-16.

66. Breeman WAP, de Blois E, Bakker WH, Krenning EP. Radiolabeling DOTA-peptides with $90 \mathrm{Y}$ and $177 \mathrm{Lu}$ to a high specific activity. In: Chinol M, Paganelli G, editors. Radionuclide peptide cancer therapy. New York: Taylor \& Francis; 2006. p. 119-26.

67. Menda Y, O'Dorisio MS, Kao S, Khanna G, Michael S, Connolly $\mathrm{M}$, et al. Phase I trial of 90Y-DOTATOC therapy in children and young adults with refractory solid tumors that express somatostatin receptors. J Nucl Med. 2010;51:1524-31.

68. Schmidt M, Baum RP, Simon T, Howman-Giles R. Therapeutic nuclear medicine in pediatric malignancy. Q J Nucl Med Mol Imaging. 2010;54:411-28.

69. Stabin MG, Sparks RB, Crowe E. OLINDA/EXM: the secondgeneration personal computer software for internal dose assessment in nuclear medicine. J Nucl Med. 2005;46:1023-7.

70. RADAR (RAdiation Dose Assessment Resource) [Internet]. Available from: www.doseinfo-radar.com.

71. Siegel JA, Thomas SR, Stubbs JB, Stabin MG, Hays MT, Koral $\mathrm{KF}$, et al. Techniques for quantitative radiopharmaceutical biodistribution data acquisition and analysis for use in human radiation dose estimates. MIRD Pamphlet No.16. J Nucl Med. 1999;40: S37-61.

72. Foster D, Barret P. Developing and testing integrated multicompartment models to describe a single-input multiple-output study using the SAAM II software system. In: Stelson A, Stabin M, Sparks R, editors. Proceedings of the Sixth International Radiopharmaceutical. Dosimetry Symposium, Oak Ridge Institute for Science and Education; 1996 May 7-10; Oak Ridge, TN: Associated Universities; 1998
73. Sgouros G. Dosimetry of internal emitters. J Nucl Med. 2005;46 Suppl 1:18S-27S.

74. Forrer F, Krenning EP, Kooij PP, Bernard BF, Konijnenberg M, Bakker WH, et al. Bone marrow dosimetry in peptide receptor radionuclide therapy with $[177 \mathrm{Lu}-\mathrm{DOTA}(0), \operatorname{Tyr}(3)]$ octreotate. Eur J Nucl Med Mol Imaging. 2009;36:1138-46.

75. Cremonesi M, Ferrari M, Bodei L, Tosi G, Paganelli G. Dosimetry in peptide radionuclide receptor therapy: a review. J Nucl Med. 2006;47:1467-75.

76. Cremonesi M, Botta F, Di Dia A, Ferrari M, Bodei L, De Cicco C, et al. Dosimetry for treatment with radiolabelled somatostatin analogues. A review. Q J Nucl Med Mol Imaging. 2010;54:37-51.

77. Minarik D, Ljungberg M, Segars P, Gleisner KS. Evaluation of quantitative planar $90 \mathrm{Y}$ bremsstrahlung whole-body imaging. Phys Med Biol. 2009;54:5873-83.

78. Walrand S, Flux GD, Konijnenberg MW, Valkema R, Krenning EP, Lhommel R, et al. Dosimetry of yttrium-labelled radiopharmaceuticals for internal therapy: $86 \mathrm{Y}$ or $90 \mathrm{Y}$ imaging? Eur J Nucl Med Mol Imaging. 2011;38:S57-68.

79. Forrer F, Uusijärvi $\mathrm{H}$, Waldherr $\mathrm{C}$, Cremonesi $\mathrm{M}$, Bernhardt $\mathrm{P}$, Mueller-Brand J, et al. A comparison of 111In-DOTATOC and 111In-DOTATATE: biodistribution and dosimetry in the same patients with metastatic neuroendocrine tumours. Eur J Nucl Med Mol Imaging. 2004;31:1257-62.

80. Rodrigues M, Traub-Weidinger T, Li S, Ibi B, Virgolini I. Comparison of 111In-DOTA-DPhe1-Tyr3-octreotide and 111In-DOTAlanreotide scintigraphy and dosimetry in patients with neuroendocrine tumours. Eur J Nucl Med Mol Imaging. 2006;33:532-40.

81. Forster GJ, Engelbach MJ, Brockmann JJ, Reber HJ, Buchholz HG, Macke HR, et al. Preliminary data on biodistribution and dosimetry for therapy planning of somatostatin receptor positive tumours: comparison of 86Y-DOTATOC and 111In-DTPAoctreotide. Eur J Nucl Med. 2001;28:1743-50.

82. Helisch A, Förster GJ, Reber H, Buchholz HG, Arnold R, Goke B, et al. Pre-therapeutic dosimetry and biodistribution of 86Y-DOTAPhe 1-Tyr3-octreotide versus $111 \mathrm{In}$-pentetreotide in patients with advanced neuroendocrine tumours. Eur J Nucl Med Mol Imaging. 2004;31:1386-92.

83. Kwekkeboom DJ, Kooij PP, Bakker WH, Macke HR, Krenning EP. Comparison of 111In-DOTA-Tyr3-octreotide and 111InDTPA-octreotide in the same patients: biodistribution, kinetics, organ and tumor uptake. J Nucl Med. 1999;40:762-7.

84. Hindorf C, Chittenden S, Causer L, Lewington VJ, Mäcke HR, Flux GD. Dosimetry for (90)Y-DOTATOC therapies in patients with neuroendocrine tumors. Cancer Biother Radiopharm. 2007;22:130-5.

85. Kwekkeboom DJ, Bakker WH, Kooij PP, Konijnenberg MW, Srinivasan A, Erion JL, et al. [177Lu-DOTAOTyr3]octreotate: comparison with [111In-DTPAo]octreotide in patients. Eur J Nucl Med. 2001;28:1319-25.

86. Cremonesi M, Ferrari M, Bodei L, Bartolomei M, Chinol M, Mei $\mathrm{R}$, et al. Dosimetry in patients undergoing 177Lu-DOTATATE therapy with indications for 90Y- DOTATATE. Eur J Nucl Med Mol Imaging. 2006;33:S102.

87. Sandström M, Garske U, Granberg D, Sundin A, Lundqvist H. Individualized dosimetry in patients undergoing therapy with 177Lu-DOTA-D-Phe1-Tyr3-octreotate. Eur J Nucl Med Mol Imaging. 2010;37:212-25.

88. Rolleman EJ, Valkema R, de Jong M, Kooij PP, Krenning EP. Safe and effective inhibition of renal uptake of radiolabelled octreotide by a combination of lysine and arginine. Eur J Nucl Med Mol Imaging. 2003;30:9-15.

89. de Keizer B, van Aken MO, Feelders RA, de Herder WW, Kam $\mathrm{BL}$, van Essen M, et al. Hormonal crises following receptor radionuclide therapy with the radiolabeled somatostatin analogue [177Lu-DOTA0,Tyr3] octreotate. Eur J Nucl Med Mol Imaging. 2008;35:749-55. 
90. Valkema R, Pauwels SA, Kvols LK, Kwekkeboom DJ, Jamar $\mathrm{F}$, de Jong $\mathrm{M}$, et al. Long-term follow-up of renal function after peptide receptor radiation therapy with 90Y-DOTA0, Tyr3-octreotide and 177Lu-DOTA0,Tyr3-octreotate. J Nucl Med. 2005;46:83S-91S.

91. Teunissen JJ, Krenning EP, de Jong FH, de Rijke YB, Feelders RA, van Aken MO, et al. Effects of therapy with [177Lu-DOTA0, Tyr3] octreotate on endocrine function. Eur J Nucl Med Mol Imaging. 2009;36:1758-66.

92. van Essen M, Krenning EP, Bakker WH, de Herder WW, van Aken MO, Kwekkeboom DJ. Peptide receptor radionuclide therapy with 177Lu-octreotate in patients with foregut carcinoid tumors of bronchial, gastric and thymic origin. Eur J Nucl Med Mol Imaging. 2007;34:1219-27.

93. Beutler D, Avoledo P, Reubi JC, Mäcke HR, Müller-Brand J, Merlo A, et al. Three-year recurrence-free survival in a patient with recurrent medulloblastoma after resection, high-dose chemotherapy, and intrathecal Yttrium-90-labeled DOTA0-DPhe1-Tyr3-octreotide radiopeptide brachytherapy. Cancer. 2005;103:869-73.

94. Villard L, Romer A, Marincek N, Brunner P, Koller MT, Schindler $\mathrm{C}$, et al. Cohort study of somatostatin-based radiopeptide therapy with [(90)Y-DOTA]-TOC versus [(90)Y-DOTA]-TOC plus [(177)Lu-DOTA]-TOC in neuroendocrine cancers. J Clin Oncol. 2012;30:1100-6.

95. Kunikowska J, Królicki L, Hubalewska-Dydejczyk A, Mikołajczak R, Sowa-Staszczak A, Pawlak D. Clinical results of radionuclide therapy of neuroendocrine tumours with 90Y-DOTATATE and tandem 90Y/177Lu-DOTATATE: which is a better therapy option? Eur J Nucl Med Mol Imaging. 2011;38:1788-97.

96. Arnold R, Chen YJ, Costa F, Falconi M, Gross D, Grossman AB, et al. ENETS Consensus Guidelines for the Standards of Care in Neuroendocrine Tumors: follow-up and documentation. Neuroendocrinology. 2009;90:227-33.

97. World Health Organization. WHO handbook for reporting results of cancer treatment. Geneva: World Health Organization; 1979. Available from: http://whqlibdoc.who.int/offset/WHO_OFFSET_ 48.pdf

98. Green S, Weiss G. Southwest Oncology Group standard response criteria, endpoint, definitions and toxicity criteria. Invest New Drugs. 1992;10:239-53.

99. Van Persijn Van Meerten EL, Gelderblom H, Bloem J. RECIST revised: implications for the radiologist. A review article on the modified RECIST guideline. Eur Radiol. 2010;20:1456-67. 